\title{
Toddler foods on the Irish market - snack attack!
}

\author{
S. Taleghani ${ }^{1}$, C.J Geraghty ${ }^{1}$, S. O’Mahony ${ }^{1}$, O.C. Lyons ${ }^{1,2}$, C. B. O’Donovan ${ }^{1}$, \\ C.M. Donovan ${ }^{1}$ and M.A.T. Flynn ${ }^{1,2}$ \\ ${ }^{1}$ Food Safety Authority of Ireland, Dublin 1, Republic of Ireland and ${ }^{2}$ Nutrition Innovation Centre for Food and \\ Health, Ulster University, Coleraine, BT52 1SA, UK
}

This abstract was awarded the Yakult prize for best undergraduate student presentation.

Due to their rapid growth and development, older infants ( $\geq 6$ months) and young children (1-3 years) are vulnerable and foods targeting this age are regulated under Directive 2006/125 EC ${ }^{(1)}$. In Ireland, a survey of foods targeting older infants deemed $15 \%$ to be inappropriate due to levels of added fat, sugar or salt and lack of essential nutrients ${ }^{(2)}$. The aims of this study are to examine 'toddler foods' (foods targeting children aged 1-3 years) legally placed on the Irish market and to assess the appropriateness of such foods.

Data was collected on 'toddler foods' (foods targeting young children (1-3 years), excluding formula milks) marketed in Ireland between August and November 2017. Information collected included brand/name of food product, packaging type, nutrition information, portion size, meal type and presence of nutrition and health claims. 'Toddler foods' primarily based on cereal, milk or fruit were deemed appropriate. All other 'toddler foods' were compared with healthier versions of relevant adult foods for fat, saturated fat and sugar content. 'Toddler foods' that matched adult foods which are not recommended as part of a healthy diet (e.g. biscuits, crisps) were categorised as inappropriate. The appropriateness of foods was examined according to meal type. 'Toddler foods' were also categorised according to the packaging they were presented in (e.g. packet $v s$. pouch) and compared for nutrients per $100 \mathrm{~g}$, appropriateness and presence of nutrition and health claims (see table).

\begin{tabular}{|c|c|c|c|c|c|c|c|}
\hline Per $100 \mathrm{~g}$ & Packet (n53) & $\begin{array}{c}\text { Box } \\
(\mathrm{n} 10)\end{array}$ & $\begin{array}{c}\text { Pot } \\
\text { (n34) }\end{array}$ & $\begin{array}{c}\text { Pouch } \\
\text { (n13) }\end{array}$ & $\begin{array}{c}\text { Bottle } \\
\text { (n5) }\end{array}$ & $\begin{array}{c}\text { Bar } \\
(\mathrm{n} 11)\end{array}$ & p-value \\
\hline $\begin{array}{l}\text { Energy } \\
\text { (kcal) }\end{array}$ & $\begin{array}{l}423 \\
(44-533)\end{array}$ & $\begin{array}{l}433 \\
(337-471)\end{array}$ & $\begin{array}{l}72 \\
(48-101)\end{array}$ & $\begin{array}{l}68 \\
(36-429)\end{array}$ & $\begin{array}{l}16 \\
(15-93)\end{array}$ & $\begin{array}{l}403 \\
(285-410)\end{array}$ & $<0.01$ \\
\hline Fat & 12 & 13 & 2 & 0 & 0 & 15 & $<0.01$ \\
\hline$(\mathrm{g})$ & $(0-25)$ & $(1-17)$ & $(1-4)$ & $(0-13)$ & $(0-0)$ & $(1-16)$ & \\
\hline Sat. Fat & 1 & 3 & 1 & 0 & 0 & 2 & $<0.01$ \\
\hline (g) & $(0-15)$ & $(0-7)$ & $(0-3)$ & $(0-4)$ & $(0-0)$ & $(0-2)$ & \\
\hline Sugar & 13 & 21 & 3 & 9 & 4 & 26 & $<0.01$ \\
\hline (g) & $(0-68)$ & $(2-68)$ & $(1-9)$ & $(2-27)$ & $(3-4)$ & $(19-58)$ & \\
\hline Fibre & 4 & 4 & 1 & 0 & 0 & 6 & $<0.01$ \\
\hline (g) & $(0-9)$ & $(0-11)$ & $(0-3)$ & $(0-8)$ & $(0-0)$ & $(2-12)$ & \\
\hline Salt & $0 \cdot 1$ & $0 \cdot 3$ & $0 \cdot 1$ & 0 & 0 & 0 & $<0.01$ \\
\hline (g) & $(0-2)$ & $(0-1)$ & $(0-0 \cdot 3)$ & $(0-0)$ & $(0-0)$ & $(0-0)$ & \\
\hline$\%$ appropriate $(n)$ & $42(22)$ & $50(5)$ & 97 (33) & $62(8)$ & $60(3)$ & $9(1)$ & $<0.01$ \\
\hline
\end{tabular}

Values are presented as medians (minimum-maximum) per $100 \mathrm{~g}$. Differences across nutrition information between packaging types were assessed using Kruskal-Wallis $\mathrm{H}$ test. Differences between proportions of appropriate foods were assessed using Chi-Square.

As shown in the table, there were significant nutritional differences among 'toddler foods' in terms of their nutritional content and the proportions found to be appropriate. A total of 126 'toddler foods' were found. Almost all ( $97 \%$ ) 'toddler foods' presented in pots were deemed appropriate, and $86 \%$ of these were lunch/dinner meal types. Over half $(53 \%)$ of the 'toddler foods' were snacks, many $(62 \%)$ of which were deemed inappropriate. These foods were more likely to be presented in packets $(64 \%)$ and boxes $(11 \%)$. Apart from being lower in salt, such snacks were nutritionally comparable with similar snack foods on the general market. Compared with reduced fat crisps, 50\% (n9) of 'toddler vegetable-based puffed snacks' were higher in total fat, while $67 \%(n 12)$ were higher in saturated fat. All 'toddler bars' were higher in sugar compared with cereal bars on the general market, while almost three quarters $(67 \%, n 8)$ of 'toddler fruit snacks' were higher in sugar than 'reduced sugar' jelly sweets $(59 \mathrm{~g} v$ s. $39 \mathrm{~g}$ sugar per $100 \mathrm{~g}$ respectively). The proportion of appropriate $v s$. inappropriate foods bearing claims were comparable $(72 \% v s .57 \%$ respectively, $\mathrm{p}=0.09)$.

This study shows lunch/dinner 'toddler foods' sold in pots are the most appropriate options. However, a high proportion (43\%) of 'toddler foods' are inappropriate and these are mainly snacks sold in packets, boxes and as bars. Parents and caregivers need to be made aware that such snacks are inappropriate, despite carrying nutrition and health claims.

1. European Commission Directive 2006/125/EC on processed cereal-based foods and baby foods for infants and young children https://www.fsai.ie/ uploadedFiles/Dir2006_125.pdf (Accessed on 16/03/2018)

2. Bennett A, O'Connor A, Flynn MAT et al. (2012) Irish Medical Journal 105, 266-268. 